\title{
Humidity and Temperature Variation in Building Stones: Comparing Simulation Results and Impedance Measurements
}

\author{
Nayara R.M. Sakiyama ${ }^{1,2}$, S. Bina M. Hejazi ${ }^{1}$, Jürgen Frick ${ }^{1}$, Frank Lehmann ${ }^{1}$, Harald Garrecht ${ }^{1}$ \\ ${ }^{1}$ University of Stuttgart, Stuttgart, Germany \\ ${ }^{2}$ Federal University of Mucuri and Jequitinhonha Valleys, Teófilo Otoni, Brazil
}

\begin{abstract}
Non-destructive measures regarding building dampness assessment plays a vital role within the constructions health evaluation. In this sense, this research investigates the relationship between impedance measurements and moisture content inside building porous materials. 1D simulations involving computational modelling of coupled heat and moisture transport in Delphin and WUFI software were carried out using data from a three-year test that investigated the electric current behaviour considering five types of sandstones under temperatureand humidity-controlled experimental conditions. The simulated results showed that impedance measurements have a direct and clear inverse response to the moisture content and, with further research, could be a reliable alternative for quantitative in-situ building dampness estimations.
\end{abstract}

\section{Introduction}

Moisture and temperature changes in buildings' stones can negatively affect both construction thermal properties and structure. Especially when performing energy retrofits, moisture buffering from building fabric is an important topic (Webb 2017), since it affects energy storage and therefore energy gain/losses through building envelope. Macher et al. (2017) affirm that building dampness has various causes and is among the most pervasive indoor environmental apprehensions. Besides the influence on the envelope energy balance, they also point that capillary water penetration with dissolved salts causes corrosion, mould growth and other pathologies that can be associated to dampness-related health effects in buildings. Often, the water intake is only visually identified, which generally means that the damages are at an advanced state leading to a complex repair.

Moisture content (MC) assessment plays a significant role in historical heritage constructions, where walls commonly have a high moisture and salt content. Therefore, it is important that investigations of buildings with suspected moisture problems are able to identify areas of excess moisture, as well as determining the urgency of any necessary mitigations, identifying path spreads to guide the intervention process. This requires both an understanding of the moisture behaviour inside the building structure, which also involves a material characterization, including its moisture storage function, and the development of intelligent moisture-monitoring systems (Zhao et al. 2012). Among the solutions to achieve this demand are advanced moisture monitoring and control technologies, which can assure effective and efficient maintenance and retrofit of architectural infrastructures and their functionalities. So far, a wide range of moisture-sensing devices and instruments has been developed for meeting various in-field moisturemeasuring requirements. Impedance measurement is one of them, and in contrast to separate analyses over time, the electrical impedance of a structure can be continuously monitored in combination with ambient conditions (Lehmann, Krüger 2014; Lehmann 2018).

Moreover, building simulations that address hygrothermal properties are likewise a powerful and widespread tool. Investigations related to moisture content in pore materials and its influence in energy performance or moisture issues, such as mould growth or frost damage risks, have been the focus of current scientific research (Abuku et al. 2009); (Govaerts et al. 2018); (Yu et al. 2012); (Zhao et al. 2017).

In this sense, this research seeks to compare the impedance results of a long-term laboratorial test with the moisture content outputs from hygrothermal software. Relative humidity and temperature data are used to validate the numerical model and the work aims to show a correlation between impedance measurements and simulated moisture content values. The goal is not only to be able to compare building measurements and laboratorial test, but considering further researches, also to be able to estimate the water activity within the structures under investigation from the in situ impedance measurements.

\section{Moisture assessment in building porous materials}

Dampness-monitoring techniques and related investigations have been carried out over the past years in order to better understand the moisture behaviour inside building materials and its impacts on thermal conductivity (Kočí et al. 2017). Among the methods of MC measurements found in literature, one uses a hot wire to assess the material's volumetric heat capacity. The moisture content is inferred from the change of volumetric heat capacity before and after moisture acquirement (Zhang et al. 2015). Dynamic thermal analysis, using thermal-circuit modelling approach and nodal solution method were also performed by (Kontoleon e Giarma 2016), where they showed the influence of relative humidity and layer thickness variation on the decrement factor and time lag, the indexes they have chosen. Hoła et al. (2012) applied a general algorithm of impedance to create impedance images, 
exploiting the correlation between conductivity distribution and material moisture for an object with a known internal structure. When comparing different moisture measurements, using weight, relative humidity (RH), electrical resistance, capacitance and inductancecapacitance resonant sensors, (Zhao et al. 2012) affirm that RH sensors are not a good indicator of MC due to sensor saturation. The authors pointed capacitive sensing as a good method to accomplish MC measurement, remarking that it is easily constructed and cost effective for assessing moisture content inside building structures and materials.

There are several international standards where one can find methods to measure moisture and water content in building materials, regarding its conservation and type. Recently, a most comprehensive standard addressing the cultural heritage establishes a priority of methods; first, the absolute methods and then, relative methods, with electric resistance and capacitance among the latter (Camuffo 2018).

Since RH measures alone cannot indeed show the moisture behaviour inside the materials, and knowing that impedance is an indicator of humidity changes in porous materials, it is possible to use it to detect moisture content in buildings and buildings components in the dampness early stages. Therefore, impedance measurements present itself as a monitoring system to ensure the preservation and rehabilitation of valuable historic heritage buildings.

As an example, one has Lehmann`s research (2018) that shows a practical application of impedance monitoring at the Danube Spring monument, located in the town of Donaueschingen in southern Germany. Over the years, the artwork had suffered severe deterioration leading to a first examination carried out in 2008 , to determine the moisture content and salt load of the ornamented sandstone that revealed an extreme degree of moisture penetration up to saturation. With the electrical impedance measurement, sudden drops in the impedance frequency are an indicator for precipitation and sudden upward steps for frost, which can directly compromise structural integrity. Another practical example is the work from Reichling (2014), that studies the applicability of Archie's law on concrete in order to correlate resistivity values with saturation degrees and pore structure parameters.

Additionally, moisture transfer prediction has also been integrated to simulation tools. Some building models and applications for accurate assessment of moisture impact in building materials using different software are reported in (Woloszyn e Rode 2008), showing how numerical analysis are also essential tools at the building moisture estimation. However, the interaction between measurements and numerical simulations frequently present discrepancies (Berger et al. 2017), besides being restricted to MC values, and no electric resistance, capacitance is simulated.

In this sense, creating numerical models in WUFI and DELPHIN software and using the experimental data to compare directly $\mathrm{MC}$ and impedance results, thus validating the models. In addition, component-level analysis also assist the understanding of the materials hygrothemal properties and their correlation with the electrical impedance measurement performance, the main objective of this work.

\section{Methods}

\section{Chamber and sandstone specimens}

Impedance measurements validity in relation to the MC inside porous materials was first carried out in a long-term test using a desiccator cabinet placed in a temperaturecontrolled laboratory (Kesseoglou 2016). Five types of sandstones cut into uniform cubes, each having a side length of $40 \mathrm{~mm}$ (Figure 1), and a wide properties range (Table 1) were place inside the chamber. The water adsorption was varied exclusively by changes in the humidity using saturated aqueous salt solutions.

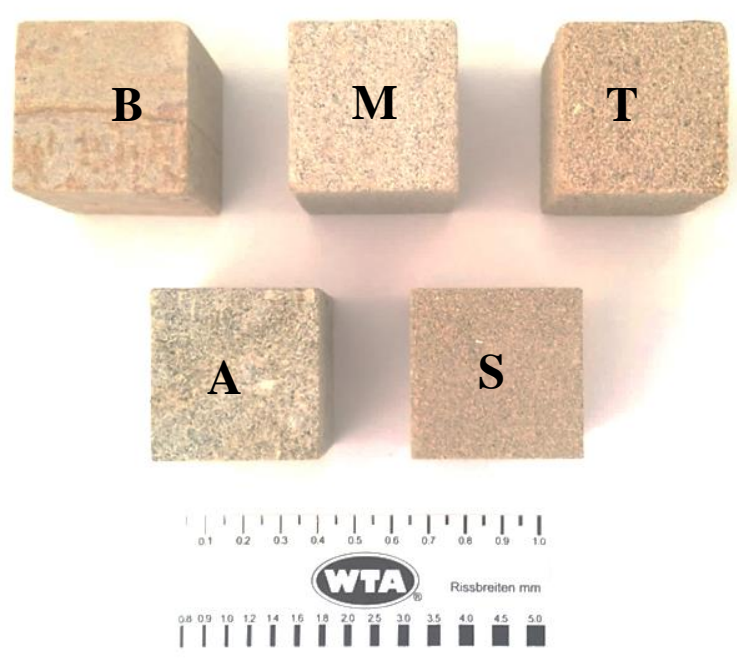

B: Burgpreppacher, M: Main sandstone white-grey

T: Trebgaster new red, A: Abbacher green, S: Sander reed

Figure 1: Analysed sandstones (Kesseoglou 2016)

The considered sandstone varieties were selected from southern Germany. In detail Abbacher green sandstone, Burgpreppacher sandstone, Main sandstone white-grey, Sander reed sandstone and Trebgaster new red sandstone (Figure 1). Such material was chosen because it exhibits a largely interconnected porous network, thus allowing the study of impedance measurements for qualitative moisture monitoring of porous building materials.

The data collection regarding the experiment was carried out with the help of the self-developed impedance measurement system (Lehmann; Krüger, 2014). For the placement of the sensors (electrical current, temperature and humidity), three holes were drilled on one side of each stone forming an isosceles triangle with $20 \mathrm{~mm}$ leg length. 
Table 1: Properties of the analysed stones.

\begin{tabular}{|c|c|c|c|}
\hline \multirow{3}{*}{ Stones } & \multicolumn{3}{|c|}{ Properties } \\
\hline & $\begin{array}{l}\text { Dry thermal } \\
\text { conductivity }\end{array}$ & $\begin{array}{c}\text { Dry } \\
\text { bulk } \\
\text { density }\end{array}$ & Porosity \\
\hline & $\begin{array}{c}\lambda \\
\mathrm{W} / \mathrm{mK}\end{array}$ & $\begin{array}{c}\rho \\
\mathrm{Kg} / \mathrm{m}^{3}\end{array}$ & $\begin{array}{c}\Phi \\
\mathrm{m}^{3} / \mathrm{m}^{3}\end{array}$ \\
\hline A & 2,87 & 2262,78 & 0,146 \\
\hline B & 2,94 & 2115,14 & 0,201 \\
\hline M & 1,71 & 2157,73 & 0,185 \\
\hline$S$ & 2,46 & 2100 & 0,209 \\
\hline \multirow[t]{2}{*}{$\mathrm{T}$} & 2,3 & 2254,21 & 0,149 \\
\hline & \multicolumn{3}{|c|}{ Properties } \\
\hline \multirow{2}{*}{ Stones } & $\begin{array}{l}\text { Water vapour } \\
\text { resistance }\end{array}$ & $\begin{array}{c}\text { Specific } \\
\text { heat } \\
\text { capacity }\end{array}$ & $\begin{array}{c}\text { Water } \\
\text { uptake } \\
\text { coefficient }\end{array}$ \\
\hline & $\begin{array}{l}\mu \\
-\end{array}$ & $\underset{\mathrm{J} / \mathrm{kgK}}{\mathrm{Cp}}$ & $\begin{array}{c}\mathrm{Aw} \\
\mathrm{Kg} /\left(\mathrm{m}^{2} \sqrt{ } \mathrm{s}\right)\end{array}$ \\
\hline A & 63,73 & 874,501 & 0,0125554 \\
\hline B & 34,12 & 846,49 & 0,0237859 \\
\hline M & 148,41 & 814,544 & 0,00904087 \\
\hline$S$ & 16 & 800 & 0,3685 \\
\hline $\mathrm{T}$ & 58,77 & 850 & 0,00639373 \\
\hline
\end{tabular}

The laboratory experiment lasted 3 years (22.03.201320.01.2016). Long-term measurements were carried out to research the gradually adapting material moisture of different sandstones caused by a change in the ambient relative humidity between 54 and $100 \%$. Figure 2 shows the RH, temperature and impedance mean measurements of three samples of the respective five types of sandstone over time.

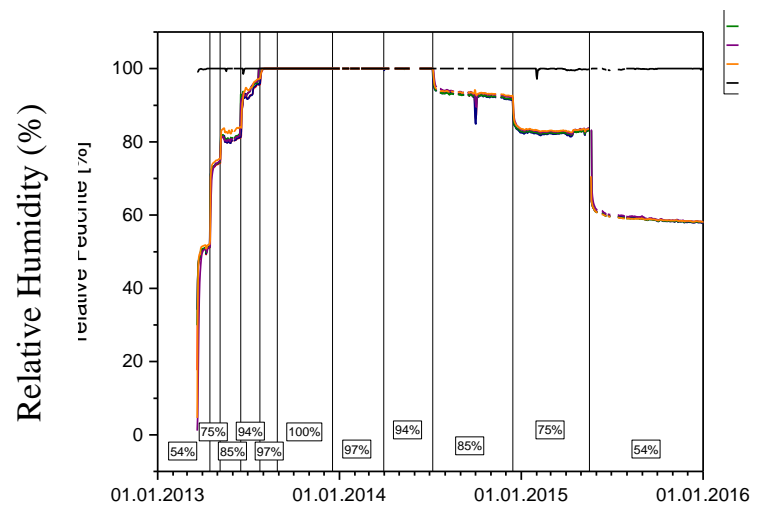

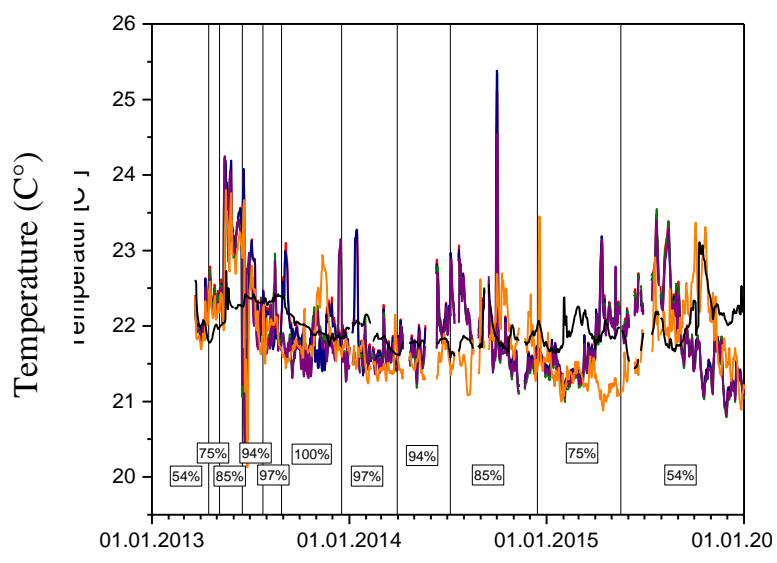
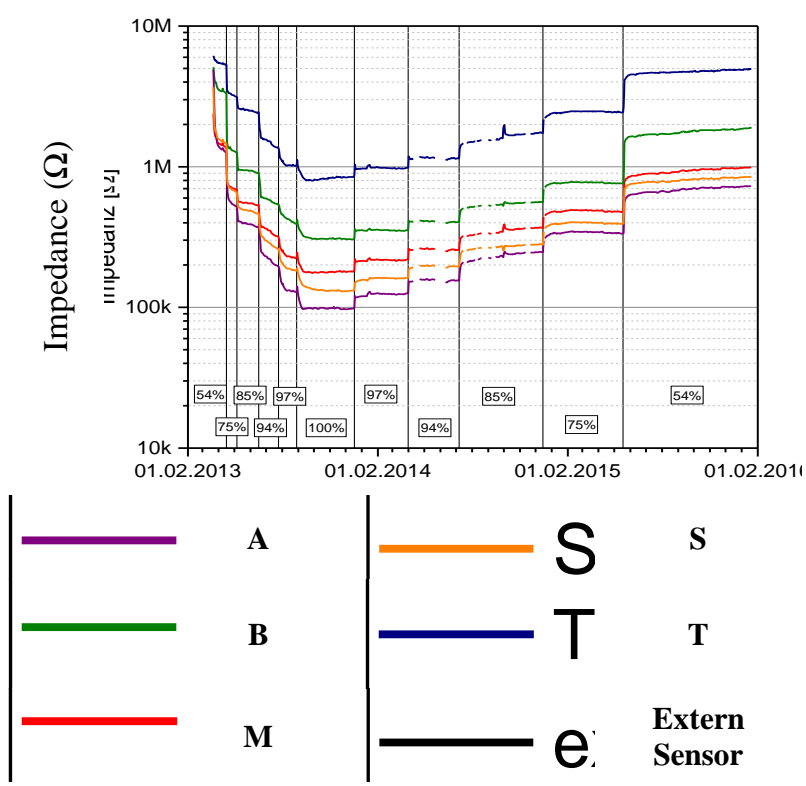

Figure 2: Data profile for the five analysed stones over the entire experimental period (Kesseoglou 2016)

\section{D WUFI and DELPHIN numerical simulations}

The 1D numerical models created using the DELPHIN 5.0 (B.C. Bauklimatik Dresden 2017) and WUFI 4.0 (I.B.P. Fraunhofer 2015) were developed in order to verify the laboratorial test findings and correlate impedance measurements and moisture content outcomes from the simulations.

Exterior boundary condition used as input, the hourly data of temperature and relative humidity measured inside the chamber (experimental data). As for the interior boundary condition, which corresponds to the laboratory's stable environment, the values were assumed as the same as in the lab tests, set to a constant temperature and Relative Humidity, respectively $21^{\circ} \mathrm{C}$ and $55 \% \mathrm{RH}$. The 1D numerical models had the same dimensions as the sample stones used in the experimental test $(40 \mathrm{~mm})$ and considered the properties listed in Table 1 . The computational grid size was composed by elements that varied from $2 \mathrm{~mm}$ (at the boundaries) to $7 \mathrm{~mm}$ thick (in the middle).

As outcomes, both WUFI and DELPHIN gave temperature $\left({ }^{\circ} \mathrm{C}\right), \mathrm{RH}(\%)$ and moisture content $(\mathrm{Kg})$ 
extracted at the same position were the sensors were located during the experimental test.

\section{Results and Discussion}

\section{Laboratorial campaign}

The experimental results showed that temperature, relative humidity, pore structure and surface area influenced the impedance, which is particularly dependent on material MC. Therefore, impedance decreased with increasing relative humidity due to the greater water content in the sandstones, hence rising the conductivity. Similarly, low humidity values led to high impedances (Kesseoglou, 2016).

However, since the sensors do not assess quantitative MC values, the simulation results are worthy to establish this direct relationship between impedance and the material hygrothermal behaviour.

\section{Numerical simulations}

WUFI and DELPHIN numerical models correlated the moisture content outcomes from the simulations with the impedance measurements and showed an association within the two features. Figure 3 shows MC outcomes $(\mathrm{Kg})$ from Delphin and impedance values $(\Omega)$ for each of the five analysed stones between July 2013 and January 2014, where RH was above $90 \%$ over the entire period. The graphics present the impedance readings of each three samples of the five analysed stones.

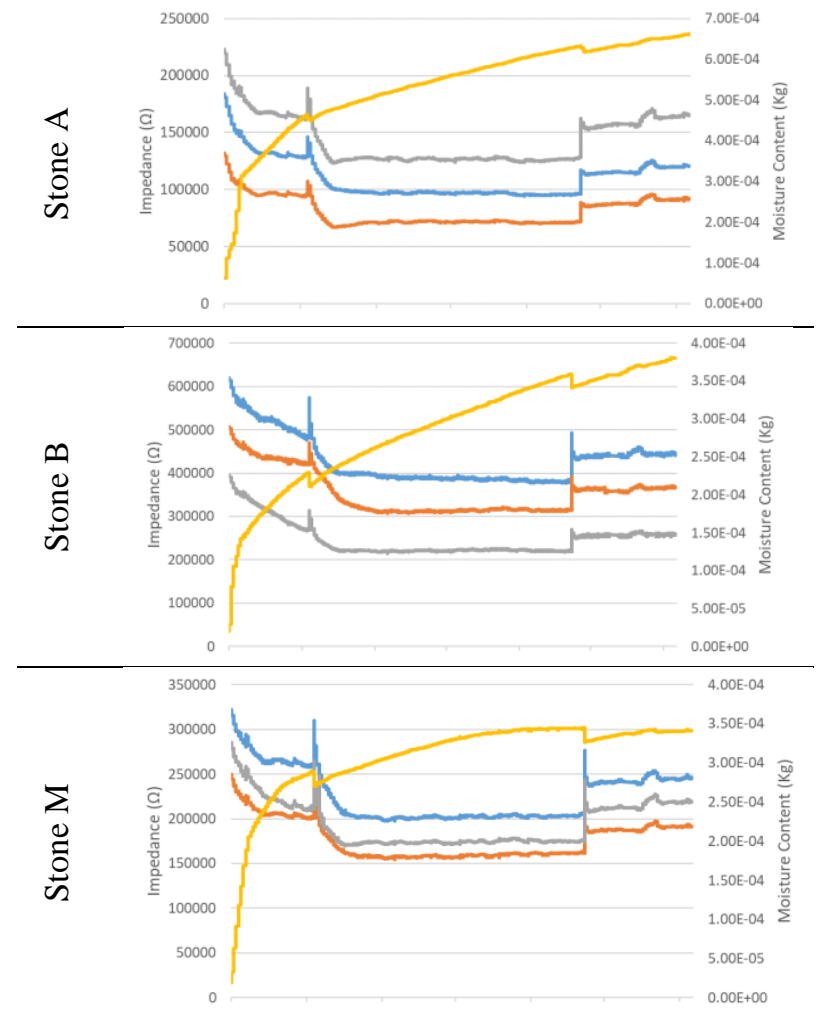

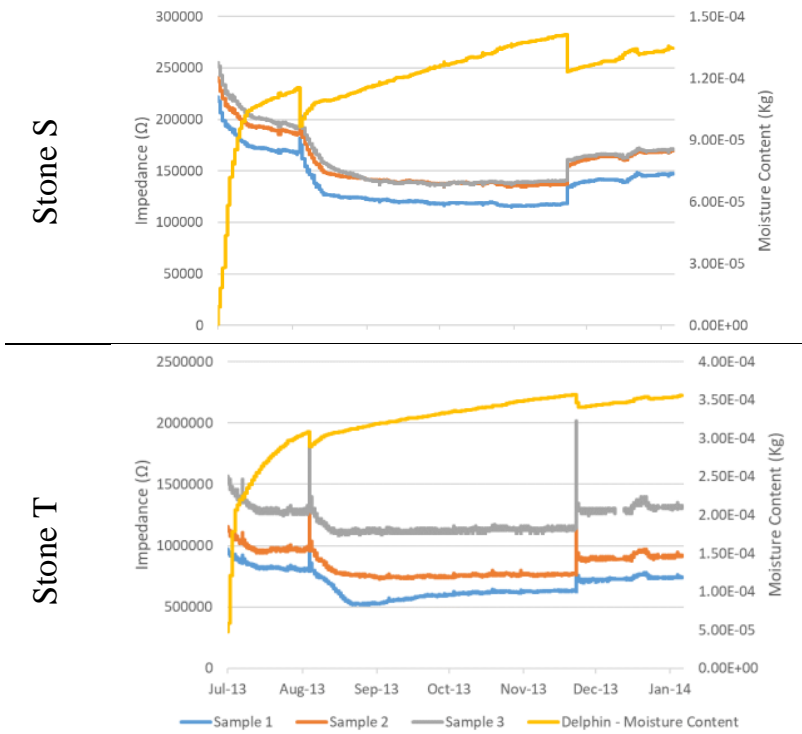

Figure 3: Simulated MC in Delphin x Measured impedance in each analysed stone

Stone A, which had the lowest measured impedance $(75000-225000 \Omega)$ and presented the highest dry bulk density $\left(\rho=2262 \mathrm{Kg} / \mathrm{m}^{3}\right)$ and the lowest porosity $(\Phi=0,14$ $\mathrm{m}^{3} / \mathrm{m}^{3}$ ) properties, was the one that obtained the maximum MC simulated values, with almost 7E-4 Kg. However, the same relationship does not appear in all investigated stones. The stone with the greatest measured impedance $(500000-1750000 \Omega)$, Stone T $(\rho=2254$ $\mathrm{Kg} / \mathrm{m}^{3}$ and $\left.\Phi=0,149 \mathrm{~m}^{3} / \mathrm{m}^{3}\right)$, presented the second lowest simulated water content, with the maximum value of $4.83 \mathrm{E}-05 \mathrm{Kg}$. In this sense, more investigations between material properties and impedance measurements, like the ones performed by Reichling (2014) with concrete specimens are needed in order to establish a reliable correlation and allow quantitative in-situ building dampness estimations. Nevertheless, it is possible to see that impedance and moisture content lines have an inverse behaviour in all cases and that impedance readings show abrupt responses that corresponds to even small MC variations.

When comparing the results of some of the tested stones (M, S and T) between the two-used software (Figure 4), one can observe that the MC lines present the same behaviour despite the difference in numerical proportion. At this figure, the impedance is inverted and the scales are adjusted in a way that the curves match.

In addition, temperature and relative humidity outcomes from both computer solvers, DELPHIN and WUFI when compared to the experimental data, showed high coefficient of determination $\left(\mathrm{R}^{2}\right)$, with 0.99 and 0.98 values, respectively, when RH is around $80 \%$. Higher or lower RH values increased the deviation, leading to poor $\mathrm{R}^{2}$ numbers (0.92-0.96). The simulated and measured results demonstrate that impedance assessments are a suitable alternative for building dampness estimation, especially when considering cultural heritage, where more invasive test cannot be considered. 


\section{Conclusion}

The work reported here describes a simple and straightforward study in the field of moisture content assessment inside porous buildings materials. By correlating impedance measurements and computational modelling of moisture transport outcomes from two software (WUFI and DELPHIN), the paper shows a direct relationship between the two analysed features. Impedance and moisture content results present an inverse behaviour in all cases and impedance readings show abrupt responses even to small $\mathrm{MC}$ variations.

With the impedance measurements, the water content can be detected both in the hygroscopic and over hygroscopic humidity range. On the other hand, although it is possible to find a link between the properties of the materials analyzed and the results found, further studies in this area, such as being able to model the relationship between impedance and moisture content and thus both validate the measurements and gain additional information about the moisture dynamics, are still necessary to improve future in-situ quantitative analysis.

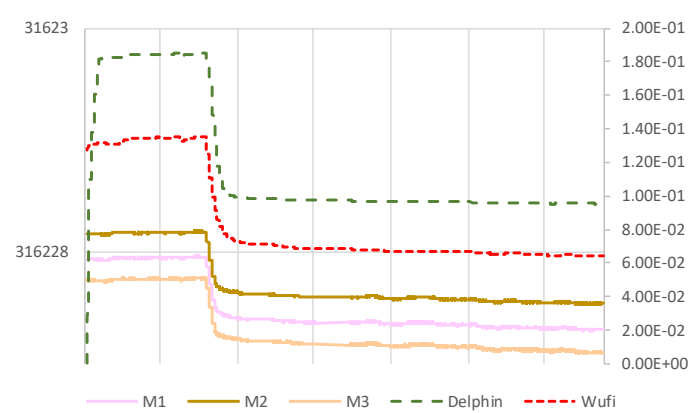

a) Stone $M$

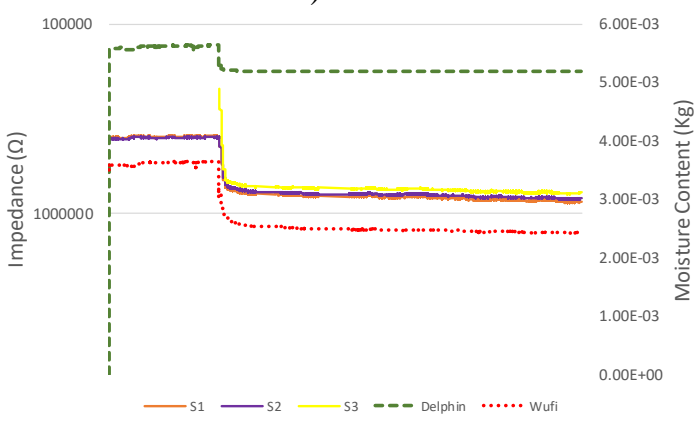

b) Stone $S$

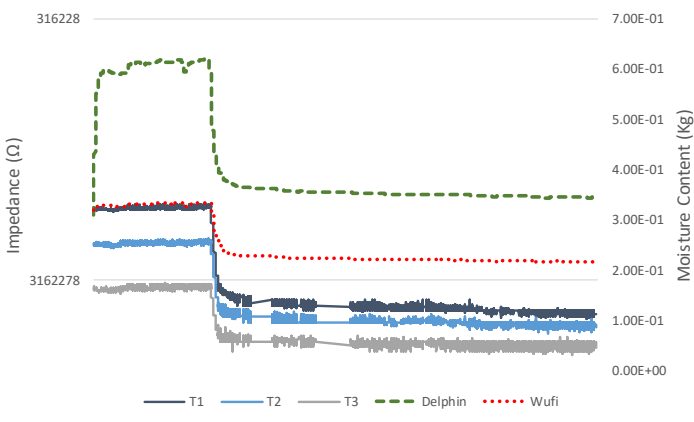

c) Stone $\mathrm{T}$

Figure 4: Simulated MC in Delphin x Measured impedance in $M, S$ and $T$ Stones

\section{References}

Abuku, M.; Janssen, H. and Roels, S (2009). Impact of wind-driven rain on historic brick wall buildings in a moderately cold and humid climate: Numerical analyses of mould growth risk, indoor climate and energy consumption. Energy and Buildings 41 (1), 101-110.

B.C. Bauklimatik Dresden (2017). Delphin. Simulation Program for the Calculation of Coupled. [Online]. Available: http://www.bauklimatikdresden.de/delphin/index.php?aLa\%C2\%BCen.

Berger, J.; Gasparin, S.; Dutykh, D. and Mendes, N. (2017). Accurate numerical simulation of moisture front in porous material. Building and Environment $118,211-224$.

Camuffo, D. (2018). Standardization activity in the evaluation of moisture content. Journal of Cultural Heritage 31, 10-14.

Frank L. and Markus K. (2014). Assessing the Risk of Salt Weathering in Sandstone by Instrumented Monitoring of the Electrical Impedance. Proceedings from EWSHM - 7th European Workshop on Structural Health Monitoring. Nantes (France), 8-11 Jully 2014. [Online]. Available: https://hal.inria.fr/hal-01022036.

Govaerts, Y.; Hayen, R.; Bouw, M. de; Verdonck, A.; Meulebroeck, W.; Mertens, S. and Grégoire, Y. (2018). Performance of a lime-based insulating render for heritage buildings. Construction and Building Materials 159, 376-389.

Hoła, J.; Matkowski, Z.; Schabowicz, K.; Sikora, J.; Nita, K. and Wójtowicz, S. (2012). Identification of moisture content in brick walls by means of impedance tomography. COMPEL 31 (6), 17741792.

I.B.P. Fraunhofer (2015). WUFI ${ }^{\circledR}$ Pro. [Online]. Available: https://wufi.de/de/software/wufi-pro/.

Kesseoglou, C. (2016). Untersuchung von Feuchteänderungen an Bauwerken mit elektrischen Impedanzmessungen. Bachelor thesis (german), Stuttgart: University of Stuttgart, 2016.

Kočí, V.; Vejmelková, E.; Čáchová, M.; Koňáková, D.; Keppert, M.; Maděra, J. and Černý, R. (2017). Effect of Moisture Content on Thermal Properties of Porous Building Materials. Int J Thermophys 38 (2), 1-12.

Kontoleon, K. and Giarma, C. (2016). Dynamic thermal response of building material layers in aspect of their moisture content. Em: Applied Energy 170, 76-91.

Lehmann, F. (2018). Instrumented monitoring of moisture and salt by electrical impedance measurements. Doctor thesis, Stuttgart: University of Stuttgart, 2018.

Macher, J. M.; Mendell, M. J.; Chen, W.and Kumagai, K. (2017): Development of a method to relate the 
moisture content of a building material to its water activity. Indoor air 27 (3), 599-608.

Reichling, K. (2014). Bestimmung und Bewertung des elektrischen Widerstands von Beton mit geophysikalischen Verfahren. Doctor thesis, Aachen: Technischen Hochschule Aachen, 2014.

Webb, A. (2017). Energy retrofits in historic and traditional buildings: A review of problems and methods. Renewable and Sustainable Energy Reviews 77, 748-759.

Woloszyn, M. and Rode, C. (2008). Tools for performance simulation of heat, air and moisture conditions of whole buildings. Building Simulation 1 (1), 5-24.

Yu, S.; Bomberg, M. and Zhang, X. (2012). Integrated methodology for evaluation of energy performance of the building enclosures: Part $4-$ material characterization for input to hygrothermal models. Journal of Building Physics 35 (3), 194-212.

Zhang, T.; Shen, R.; Lin, C.; Yin, J. and Wang, S. (2015). Measuring moisture content in a porous insulation material using a hot wire. Building and Environment 84, 22-31.

Zhao, J.; Rivera, E.; Mufti, A.; Stephenson, D. and Thomson, D. (2012). Evaluation of dielectric based and other methods for moisture content measurement in building stones. J Civil Struct Health Monit 2 (3-4), 137-148.

Zhao, J.; Grunewald, J.; Ruisinger, U. and Feng, S. (2017). Evaluation of capillary-active mineral insulation systems for interior retrofit solution. Building and Environment 115, 215-227. 